\title{
Tensões entre estado \\ e propriedade nos \\ Dois tratados sobre o \\ governo de Locke
}

Tensions between state and property

in Locke's Two treatises of government 
RESUMO: John Locke é frequentemente pensado como pai de um liberalismo que colocou a economia no centro do problema político, contribuindo para o que hoje entendemos por economias de mercado. Porém uma leitura mais problematizante de sua maior obra, Dois tratados sobre o governo, pode desfazer tal clichê e revelar outras respostas: afinal, até aonde pode ir o Estado na gerência da propriedade de seus cidadãos? O presente artigo pretende expor três leituras interpretativas dos Dois tratados que respondem a essa pergunta: uma primeira, de viés libertário, que acredita em direitos irrevogáveis de propriedade justamente adquirida; uma segunda, cunhada como comunalista, que acredita na distribuição inclusiva da propriedade pelo Estado; e uma terceira, que se apresenta como alternativa crítica às suas anteriores. É com esta última que este artigo alinhar-se-á, buscando defender que não há direito absoluto de propriedade nos Dois tratados - seja de bens, ação livre ou vida. Dadas certas condições reiteradas por Locke, o Estado poderia, sim, agir não só nos bens materiais, mas também na vida e na liberdade dos cidadãos, uma vez que existem reivindicações possíveis sobre todos esses direitos.

PALAVRAS-CHAVE: propriedade; Estado; justiça; liberdade; direito. 
ABSTRACT: John Locke is usually thought of as the father of a certain liberalism that put the economy at the heart of the political question, contributing to what we nowadays understand as market economies. But a more problematic rendering of Locke's greatest work, Two treatises on government, may dissolve such cliché and reveal other answers: how far can the State go in managing its citizens' property? This paper will present three interpretations of the Two treatises that answer such question: the first one, of a libertarian bias, which believes in irrevocable rights in property fairly acquired; a second one, called communalist, that believes in an inclusive distribution of property by the State; and a third one, that presents itself as an alternative to the previous ones. This paper will subscribe to the last one, trying to make the case that there is no absolute right in property in the Two treatises - either in goods, action or life. Given certain conditions reiterated by Locke, the State could, yes, act not only on the material goods, but also on the life and freedom of its citizens, since there are possible claims on all these rights.

KEYWORDS: property; State; justice; freedom; right. 


\section{INTRODUÇÃO}

Até aonde vai a autoridade do Estado na gerência da propriedade de seus cidadãos? Em seus Dois tratados sobre o governo, John Locke apresenta respostas cujos ecos são sentidos até hoje. Locke é inclusive tido pela maioria como pai do liberalismo que hoje sabemos ter levado às economias de mercado. Porém uma leitura mais problematizante de sua opus magna nos leva a repensar esse lugar comum.

Por um lado, Locke diz que "todo homem, quando se incorpora a qualquer sociedade política, também incorpora e submete à sociedade, por esse ato, as posses que tenha ou venha adquirir". Essas posses, afirma, "deverão ser regulamentadas pelas leis dessa sociedade" (II, §I20). Mas, por outro lado, Locke declara que o poder "não pode ter outro fim ou medida, quando estiver nas mãos do magistrado ${ }^{2}$, que o de conservar os membros da sociedade em suas vidas, liberdades e posses" (II, §I7I). Ele é bastante claro ao dizer que "o poder supremo não pode tomar de homem algum nenhuma parte de sua propriedade sem o seu próprio consentimento" (II, §I38).

Afinal, o Estado tem o direito de taxar o cidadão? De desapropriar ou redistribuir a terra?

I Seguindo notação consagrada, indicarei o tratado por números romanos (I ou II) e a respectiva seção em números arábicos.

2 Indivíduo investido de autoridade político-administrativa. 
Levanto aqui possíveis respostas, resumindo-as em três leituras interpretativas: uma de viés libertário, saída de Anarchy, State and Utopia (I974) de John Nozick, para quem Locke prevê um Estado com poder reduzidíssimo sobre a propriedade dos cidadãos; uma segunda, que chamarei de comunalista, saída de A Discourse on Property (1980) de James Tully, que acredita que a terra sempre permanece à disposição da comunidade, cabendo ao Estado constantemente redistribuí-la de maneira a que todos tenham sua porção3; e uma terceira, que denominarei crítica, originada de The Right to Private Property (1988) de Jeremy Waldron, que questiona as duas anteriores, relativizando o problema.

Tais autores centram-se muito no que contemporaneamente entendemos por propriedade, a saber: a propriedade de bens materiais - e, mais ainda, a propriedade da terra. Isso não é à toa, já que esse é o único da tríade lockeana de direitos de propriedade (vida, liberdade e bens materiais) que precisa ser adquirido - e que em seus pormenores gerou mais discórdia interpretativa. Ainda assim, tratarei de expor, ao final, algumas considerações sobre o limite do Estado na gerência da vida e liberdade de seus súditos.

\section{A LEITURA LIBERTÁRIA}

A primeira teoria defende que o direito à propriedade é conquistado para sempre ainda no estado de natureza, quando trabalham-se os recursos naturais: o que é apropriado "não pertence em comum a outros" (II, §44), sendo, portanto, um direito exclusivo daquele que se apropriou da coisa. E apropriar-se de algo, para o libertário, é aumentar seu valor. Isto poten-

3 Este seria um sistema de propriedade individual (direito exclusivo de uso), ainda que não privada (direito inclusivo de apropriação). 
cialmente melhora a vida de outros - compensando a perda de liberdade que teriam de serem donos aquela coisa (NOZICK, 1974, p. I75ss). Ainda que chegue o momento em que não reste o suficiente para os demais apropriarem (II, §27), eles poderão usar daquilo que já estará apropriado, não vendo sua situação piorada.

A leitura libertária acredita que o direito de propriedade não é anulado na passagem para o Estado civil, pois este é criado exatamente para garantir a preservação da vida, liberdade e bens de seus súditos: "o poder supremo não pode tirar a qualquer homem parte da sua propriedade sem consentimento dele" (II, §1384).

Para o libertário, o Estado que Locke defende é aquele que toma apenas as posses do súdito necessárias para a preservação dos próprios bens, vida e liberdade - por exemplo, para financiar a polícia e o sistema penal's. Se cobrar mais impostos do que necessário, o Estado força o cidadão a usar suas horas de vida para um fim alheio (NOZICK, 1974, p. I67ss).

Se o Estado tentar ir além, distribuindo as posses dos cidadãos, ele restringirá demasiado sua liberdade e interferirá continuamente na vida das pessoas - seja confiscando bens, impedindo-as de fazerem trocas, de se darem presentes ou doar (NOZICK, 1974, p. I6oss). Mas se alguém tem direito sobre X, então é este alguém (e não o governo) quem tem o direito de dar uso a X - desde que não violando a vida e a liberdade alheia.

\section{A LEITURA COMUNALISTA}

A segunda teoria, comunalista, defende que, para Locke, quando todos os recursos são apropriados, mas ainda há homens sem a chance de apropriar,

\footnotetext{
4 Cfe. também II, \$87, 88, 94, 95, г23, г24, І31, г39 е г40.

5 "É natural que todos que gozam de uma parcela de proteção paguem do que possuem a proporção necessária para mantê-la" (II, §I40).
} 
todos os direitos de propriedade são suspensos, uma vez que i) "Deus deu o mundo aos homens em comum" e ii) a lei natural manda observar a preservação de Toda Humanidade ${ }^{6}$. Ou seja, é a humanidade como um todo, criada por Deus, quem tem direito ao mundo. James Tully (I980, p. Iog) caracteriza tal direito, portanto, como inclusivo: um direito geral, já que todo homem é um possuidor em comum que, se excluído das chances de apropriação, pode reivindicar ser incluído (TULLY, I980, p. I29).

Por isso, quando acabam os recursos, todas as propriedades naturalmente adquiridas devem ser revertidas para as mãos do governo, que passa então a atribuí-las convencionalmente. De fato, Locke afirma que "todo homem, quando primeiro se incorpora a qualquer sociedade política, também incorpora e submete à sociedade, por esse ato, as posses que tenha ou venha a adquirir" (II, §I20). Tully (I980, p. I66) explana que, quando isso acontece, o Estado "é obrigado a distribuir a cada membro os direitos civis à vida, à liberdade de preservar a si e aos outros, e de demandar os bens ou meios para isso". Esse dever é conforme o que manda a lei natural da preservação máxima da humanidade.

Tal distribuição da propriedade assegura, por um lado, que todos tenham os meios necessários para a subsistência e que, por outro, todos possam trabalhar na terra, aproveitando seus frutos. Se o libertário disser que isso infringe a liberdade individual, o comunalista responderá que a liberdade humana de agir sobre os recursos da terra consiste exatamente na "Liberdade de usá-los, que Deus permitiu" (I, §39). Agir de acordo com essa liberdade, ditada pela lei natural, não é nem poderia ser um ataque à liberdade de ninguém. Pelo contrário, é agir conforme o propósito que Deus tem para a Criação.

6 Cf. II, §6, ІІ, I6, 25, І28, І29, І34, I49, І59, І68 е г82. 
Para o comunalista, a propriedade regulada e distribuída em estado civil visa ao bem público (TULLY, I980, p. I62) - e Locke teria usado "bem público" no sentido distributivo: a porção de bem a que cada membro da sociedade tem direito. Como o bem máximo seria a preservação de todos, o bem público seria o bem/preservação de cada um (§II, 6). Em outras palavras, é assegurar a vida, a liberdade e as posses de cada um dos cidadãos - e não só de uma parte (TULLY, I980, p. I63).

\section{A LEITURA CRÍTICA}

Uma terceira leitura do texto de Locke busca relativizar a tensão entre o que o Estado pode e não pode fazer em relação à propriedade de seus súditos. Por um lado, critica a teoria libertária por ter menosprezado aquilo que está na primeiríssima linha do capítulo sobre a propriedade: a lei natural nos manda preservar o máximo de seres humanos, que "tem direito à própria preservação e, consequentemente, (...) a tudo quanto a natureza fornece para a subsistência" (II, §25). Esse direito de subsistência, que é geral, acaba, por isso, impondo restrições de bem-estar geral [welfare] em qualquer sistema de propriedade, privada, compartilhada etc. (WALDRON, I988, p. 4). O problema da teoria libertária foi pensar que a propriedade tem prioridade sobre a subsistência. Mas como a razão de ser da propriedade (em sentido amplo) é a subsistência humana, direitos de propriedade não são importantes a ponto de prejudicar ou impedir a subsistência (WALDRON, I988, p. 216). Locke confirma isso ao dizer que o poder legislativo pode fazer leis para que o indivíduo aja "conforme exigir o bem público da sociedade" (II, §89). Isso pode se dar pagando mais impostos do que o libertário queria, por exemplo.

Já a teoria comunalista colapsou direito à subsistência com direito de propriedade. A "liberdade de usar" os recursos da terra não é a garan- 
tia de se apropriar deles. Ou seja: do direito à subsistência não se segue o direito à propriedade. Locke inclusive defende que, para com o homem necessitado, exista um dever de caridade. Além disso, os homens também podem trabalhar como empregados, o que garantiria sua subsistência. No que vale à terra, especialmente, Deus de fato manda o Homem trabalhar mas nem por isso manda apropriar.

Para Jeremy Waldron, é importante levar em conta que o direito natural de propriedade é apenas contingente e que surge de uma relação particular ("especial") com um recurso. Já o direito natural à subsistência (à vida) é direito geral, que vale independentemente das relações dos indivíduos com o mundo.

Falta, então, responder o que Locke quis dizer com regular a propriedade. Para essa terceira interpretação, os direitos de propriedade adquiridos no estado de natureza são retificados, confirmados na letra da lei do estado civil. O que antes era impreciso e inseguro, juridicamente falando, passa a ter uma forma, com força para se fazer cumprir, e, se não se fizer, com penalidade prevista (II, §Iз $)^{7}$. Com efeito, a lei civil, além de garantir a propriedade, serve para que "todos saibam o que lhes pertence" (II, §i36). Para Waldron, nada disso envolve revogar direitos, como previam os comunalistas.

Tampouco, porém, nada impede que as leis venham a mudar os critérios para a aquisição de futuros direitos de propriedade. Por exemplo, o governo pode vir a regular a propriedade: a) de uma área comum positivada (uma horta comunitária) 8 b) de uma área comum e negativada, pronta para apropriação individual - caso do mar para pesca, ou área de mata

7 O polêmico caso da chegada de aplicativos de transporte particular individual foi resolvido nesses parâmetros.

8 No caso de Locke, o exemplo de sistema de propriedade da terra é o English Common (II, §35). 
para caça (II, §30); ou c) dando uso para uma herança que não foi assumida por ninguém (I, §9o).

Locke afirma que a preservação será "tanto quanto possível" (II, §88), pois, já que “a lei fundamental da natureza [é] a preservação dos homens, não há sanção humana que seja válida ou aceitável contra ela". Assim, se um direito de uma propriedade atentar contra a preservação humana, ele não terá validade (II, §I35). Logo, se preciso for, os impostos podem ser aumentados acima do mínimo necessário, bastando o consentimento da maioria (II, §I42; LASLETT, I988, p. I05).

Portanto, para Waldron, os limites naturais impostos a um governo que busca o bem público são: primeiramente, o direito geral à subsistência; e, em seguida, os direitos especiais de apropriações anteriores ao estado civil.

\section{CONSIDERAÇÕES}

A teoria libertária, como apresentada por Nozick, faz um recorte bastante enviesado das ideias lockeanas. Ele toma a liberdade e a independência absolutas do estado de natureza como referências intocáveis para o estado civil. Mas, ao fazer isso, ignora precisamente a complexidade do viver-em-sociedade e as concessões que caracterizam a passagem para o estado civil, que só existem na medida em que buscam garantir a segurança e propriedade (em sentido amplo) de todos. O ponto fraco da leitura libertária em relação ao texto de Locke é superestimar a identificação das condições para a circulação de bens com critérios de valor, e não tanto com critérios morais?

Já a teoria comunalista reforça o fato de que Locke "defende a lei natural como fundação moral contra aqueles que veem a moralidade como

9 Cfe. NOZICK, 1974, p. 158 ss. 
baseada no interesse próprio ou na utilidade" (TULLY, I980, p. IOI). Em outras palavras, adonar-se conforme tal lei não é moral porque vantajoso (o que talvez configurasse a visão produtivista nozickiana). Pelo contrário: é moral porque está de acordo com a lei divina - e calha de ser vantajoso também. Tully aposta fichas na prioridade máxima do trabalho sobre a terra, com a consequente apropriação de bens, como meio para que todos encontrem subsistência. É visando a isso que seu Estado comunalista age.

Waldron muda o centro da discussão, minimizando a importância da denominada Condição de Suficiência para Apropriação ${ }^{\text {Io }}$ e chamando atenção para o que seria o Direito Geral à Subsistência (e não necessariamente à Propriedade). O Estado não é necessário para legitimar a propriedade (como supunha o comunalista), pois, se a Condição de Suficiência fosse uma restrição de necessidade (e não uma condição mínima suficiente), morrer-se-ia de fome numa situação de escassez, o que negaria exatamente o direito e o dever de garantir a vida (WALDRON, I988, p. 213). É esse Direito Geral de Subsistência, e não a Condição de Suficiência, que propõe que, em tais casos de escassez, o excedente de recursos à sobrevivência não vá para o "conforto" do proprietário (o que estaria enquadrado no mero "uso" dos recursos da terra), mas diretamente para a subsistência dos demais (WALDRON, I988, p. 214).

Além das objeções já elencadas contra as duas primeiras leituras, Waldron (I988, p. I37) também minimiza o peso da discussão a respeito da propriedade, já que "o argumento de Locke sobre a propriedade não é tanto um fim em si mesmo, mas uma parte de seu objetivo maior de fundamentar o direito popular à revolta contra qualquer governo". O esforço

Io "Apropriar-se na medida em que haja o suficiente em igual quantidade e qualidade para todos" (II, \$27). 
de Locke é mirar i) nos inconvenientes do estado de natureza, em que cada homem é juiz de seu próprio caso; e ii) nos inconvenientes do estado civil constituído em forma de monarquia absoluta, em que o Soberano é juiz de seu próprio caso: "sempre que lhe invadam a propriedade por ordem ou vontade do monarca, [o súdito] não terá meios de apelar como os que estão em sociedade devem ter" (II, §91).

Se Locke propõe mecanismos contra a insegurança relativa aos bens, a vida e a liberdade humana, é porque acredita que a monarquia absoluta é o maior risco a eles (II, §9o e 94). Somente no estado civil representativo e democrático é que se encontram segurança e tranquilidade (II, §94), já que nele as decisões não são feitas despoticamente, mas por consenso. Assim, o que os libertários superestimam como preservação absoluta da propriedade material seria, para Locke, tão somente estabilidade, garantia de defesa e salvaguarda contra o arbítrio.

As seções I38 e I39 deixam claro que o discurso de Locke sobre a propriedade deve ser lido relativamente a esses riscos de um governo absoluto - e que o direito à propriedade, ele mesmo, tampouco é absoluto: "o príncipe ou o senado, não obstante tenha poder para promulgar leis no sentido de regular a propriedade entre os súditos, uns em relação aos outros, entretanto nunca poderá ter o poder de tomar para si, no todo ou em parte, a propriedade do súdito, sem consentimento dele" (II, §i39, meus destaques).

Portanto, o que o governo não pode é "tomar para si, no todo ou em parte, a propriedade do súdito sem o consentimento dele" (II, §139). Mais precisamente: o poder supremo não tem o direito de "proceder como bem entenda e dispor arbitrariamente dos haveres dos súditos", "aumentar suas próprias riquezas e poder, tomando do povo o que achar conveniente", nem de tomar a "propriedade que lhe aprouver, dela se servir e dispor segundo o que lhe convenha" (II, §138, meu destaque). 
Porém o governo pode "regular a propriedade dos súditos uns em relação aos outros" (II, §I39). Esse é exatamente o caso da distribuição de recursos via impostos - consentida pelos súditos, obviamente, pelo que foi visto ${ }^{\text {II }}$. Os impostos não compõem um tesouro dos próprios magistrados, mas, uma vez recolhidos, são devolvidos aos súditos na forma de benfeitorias que promovam seu bem-estar. Waldron valoriza o Locke que acreditava, com otimismo, na capacidade do povo de legislar. Mesmo o recolhimento de impostos visando ao puro e simples acúmulo, como uma poupança de Estado, poderia em tese ser feito - desde que com o consentimento da maioria.

Deixo agora a discussão da propriedade material de lado. De todo modo, acredito que a validade do direito de liberdade segue os mesmos moldes do outro: o governo não poderá "arbitrariamente" cercear a ação humana (seja por toque de recolher, mandando prender ou restringindo o direito de ir-e-vir), conforme for "conveniente" ou "The aprouver". Mas, ainda assim, tais ações seriam possíveis desde que decididas por consenso, visando ao bem público. Tais casos não deveriam nos soar estranhos, já que mesmo as constituições de algumas das mais avançadas democracias preveem o uso do toque de recolher, por exemplo ${ }^{12}$.

Por fim, o mesmo pode-se dizer do direito à vida, cuja prova de sua validade apenas relativa é a defesa que Locke faz da pena de morte em articulação com a função do Estado, resumida já no início do segundo tratado:

II Locke é muito mais claro no Ensaio sobre a tolerância (anterior aos Dois tratados): "O magistrado que tem o poder de determinar formas de transferir [transferring] propriedades de um homem para outro, pode estabelecer qualquer uma, para que sejam universais, iguais e conforme [suited to] o bem-estar da sociedade." (B MS c.28)

I2 Desde os ataques terroristas de 2015 até novembro de 20I7, a França viveu sob estado de urgência. Nossa "constituição cidadã" de I988 prevê na figura do estado de sítio a "suspensão da liberdade de reunião" e a "restrição à liberdade de imprensa", além da "requisição de bens". 
O poder político é o direito de editar leis com pena de morte, e consequentemente, todas as penas menores, com vistas a regular e a preservar a propriedade, e de empregar a força do Estado na execução de tais leis e na defesa da sociedade política contra os danos externos, observando tão somente o bem público. (II, §3, meus destaques)

A pena capital será admitida em casos de afronta ("danos externos") à tríade de direitos, especialmente o próprio direito à vida - casos esses que serão previstos por "leis promulgadas e estabelecidas, que não poderão variar nos casos particulares" e que "não devem destinar-se a outro fim que não, em última análise, o bem do povo" (II, §I42, destaque do original).

Concluo, portanto, que não há propriedade absoluta nos Dois tratados - seja de bens, de ação livre ou da vida. Dadas certas condições reiteradas por Locke, o Estado poderia, sim, agir na vida, na liberdade e nos bens materiais dos súditos uma vez que existem reivindicações possíveis sobre todos esses direitos - e bastante razoáveis, até, já que relacionadas à integridade física dos cidadãos.

Locke pretende que o Estado seja apenas o meio formal de tais reivindicações. Decidir pelo toque de recolher, a prisão ou a pena de morte, quando estabelecidos por um Legislativo visando ao bem público, devem ser entendidos como causas defendidas por aqueles que se unem em sociedade civil e que buscam através dela sobreviver a agressões e outros inconvenientes.

As tensões apontadas nos Dois tratados hoje nos parecem problemáticas em razão da oposição socialismo/capitalismo liberal. No entanto, se quisermos ler Locke à margem dessas ideologias que lhe foram posteriores, é necessário dar um passo atrás dessa dicotomia. Enfim, o autor simplesmente não reconhece um conflito entre o papel do governo e a integridade da propriedade dos súditos (ASHCRAFT, I994, p. 237). John Locke "não 
era, claro, nem socialista nem capitalista, mas é fascinante encontrar elementos de ambas atitudes em sua doutrina da propriedade" (LASLETT, I988, p. I06). 


\section{REFERÊNCIAS}

ASHCRAFT, R. Locke's political philosophy. In: CHAPPELL, V. The Cambridge companion to Locke. Cambridge: Cambridge University Press, I994.

LASLETT, P. Locke's Two Treatises of Government, Cambridge: Cambridge University Press, I988.

LOCKE, J. Two treatises of government. Notas e introdução de Peter Laslett. Cambridge: Cambridge University Press, 1988.

Dois tratados sobre o governo. Trad. Julio Fischer. São Paulo: Martins Fontes, 1998 .

NOZICK, R. Anarchy, state and utopia. Oxford: Blackwell, I974.

TULLY, J. A discourse on property: John Locke and his adversaries. Cambridge: Cambridge University Press, I980.

WALDRON, J. The right to private property. Oxford: Clarendon Press, I988. 